\title{
The relationship between the formation of the cultural identity of students and the level of education
}

\author{
Stenishcheva Alisa* \\ Peoples' Friendship University of Russia, 117198 Moscow, Russia
}

\begin{abstract}
To study the consequences of the formation of the cultural identity of students and their level of education, it should be noted that it is young people who increasingly form a multicultural identity, because as they grow up, they learn different cultural beliefs and certain patterns of behavior. Ethnographic and intercultural characteristics illustrate the ways in which learners are increasingly exposed to different cultures. In that case three main pedagogical questions arise: how important is it that multicultural identity is based on direct or indirect interaction with different peoples; how the formation of cultural identity and its development can take place depending on the specific cultures involved; advantages and disadvantages in the formation of a multicultural identity, and not just an identity in general, based mainly on one cultural tradition. The purpose of this article is to describe the relationship between learning and cultural identity. Finally, the article proposes to consider several methods based on foreign and Russian literature, taking into account different points of view in the formation of students' identity.
\end{abstract}

\section{Introduction}

The global growth of intercultural contacts due to factors such as immigration, rate of movement and communication, international corporate presence are difficult to ignore in everyday life. Educators at all levels strive to meet the challenge of responding in a timely manner to the educational needs of students, both now and in the future. Although changes in different cultures are inevitable, globalization has facilitated a massive exchange of ideas from different parts of the world, and the result of this is a rapid transformation of cultures. The continuous evolution of technology, medicine, international relations, travel and the transfer of cultural values have led to education largely in close contact between different countries.

Undoubtedly, multiculturalism affects how people understand and accept themselves and others, and how they organize the living space around them [3]. Researchers and educators around the world are trying to understand the relationship between learning and the social world. Identity formation is a long and laborious process that gradually develops in the social environment. In its most general sense, multicultural education is a progressive approach

\footnotetext{
${ }^{*}$ Corresponding author: orcid.org:0000-0003-4191-1954
} 
based on educational equality and social justice. The components required for multicultural education are the reduction of interracial and gender prejudice, the empowerment of educational and social culture. All this is associated with efforts to resolve conflicts in the modern world and requires special attention from teachers. What learners absorb in class when it comes to interacting with those who are different from them influences how well they will navigate and adapt in the global world.

Diversity exists even within a society that is familiar to an individual, students must have life communication skills that are developed precisely by multicultural education. Each student comes to an educational institution with a specific set of behaviors and characteristics that make them unique and affect academic achievement in general. Moreover, students identify with certain groups in order to understand their own belonging. There is an assumption that it is extremely important for students of all ages to feel a strong need to belong to certain groups, because these groups are a source of motivation for them. The sense of belonging and cultural background are closely related concepts and usually one derives from the other. For a deeper understanding of cultural origin, it is necessary to define this term.

\section{Chief part}

The cultural background of students is of great importance, since ethnic, racial, linguistic, social, religious, economic differences can cause cultural disunity, leading to distortion or lack of motivation to learn. The teacher should be aware of the cultural identity of students and be able to identify their characteristics for learning and motivation, which, in turn, will improve academic performance. Speaking of cultural background, one cannot but touch upon the cultural experience of students. Cultural experience refers to both individual and collective events that are characteristic of a group of people with common beliefs, values, traditions, customs, practices and language. Internal transformation takes place in the context of various sociocultural aspects and has an impressive potential in personality formation [7].

General discussions of identity within traditional Western philosophy focus on personal identity, on the question of what it means for a person to identify oneself over a period of time. Thus, the most pressing of these questions, on which Western philosophy has traditionally focused on how a person's personality persists over time. It is assumed that the individual is determined on a personal level through the persistence of experiences, beliefs and memories. However, experiences and beliefs are shaped in a social context, which is usually mediated by cultural norms.

Cultural identity can also be defined as a person's personality, which includes certain experiences, upbringing, talents, skills, beliefs, values and knowledge, in other words, who he is, what is his or her status in the family, school, university, at work, surrounding environment and country. Also, another definition of such a concept as identity can be the visible and invisible areas of the self, which affect the formation of one's own personality [2]. These include ethnicity, skin color, gender, nationality, and physical and intellectual ability. Identity parameters are not fixed or predictable, instead, they respond to both a certain time frame and a willingness to change.

Multicultural identity, in turn, is understood as a multi-layered, interdependent cooperation of social status, language, race, ethnicity, values and behavior that permeates and affects almost all aspects of our lives. All of these factors affect how individuals see the world and inform it about their experiences.

The more difficult is to understand this phenomenon, since in modern living conditions, the individual's own world becomes smaller. [6]. Since it is the motivational influence on education that is the cornerstone, educators try to discover and grope the relationship between learning and the social aspect. It should be noted that the integration of the cultural component into the learning process is a rather difficult task. 
If you take a closer look at the relationship between students and try to understand the impact of their cultural identity on their learning, you will notice that social identity is quite a controversial aspect. There is a perception that a student cannot separate his or her cultural identity from the cultural knowledge that he or she gains during training. In other words, it can be assumed that there is a relationship between learning and cultural identity. The cultural identity of a student is a certain psychological shift that allows the student to focus specifically on the process of acquiring knowledge. Broadly speaking, various aspects of motivation such as confidence, intellectual curiosity, reflection on past successes and failures, rewards and punishments set the tone for the learning environment. Students can be motivated or demotivated both externally and internally. External motivated behavior is behavior for which the individual receives both internal reward and external, this also applies to punishment, and only with internal motivated behavior, the reward is usually only internal.

In that case, there is a clear connection between motivation and the formation of identity, since it is believed that cultural identity, which is formed at different time boundaries and one of the most effective external factors. The learner's desire to gain knowledge and his / her connection with the actual motivation for learning are combined. So, when teaching, it is necessary to take into account the cultural identity of students [5].

Thus, culture is an important part of the structure of society and can be defined as the way of life of a given society, including aspects such as people's attitudes towards birth and death. There are over 160 reasoned definitions of culture. It follows from this that it is very difficult to define the concept of "culture" because it has too many meanings. First of all, culture is a social product that each person develops throughout his life. And for such a definition of the word as "personality", there are four concepts of identity, namely individual differences, consistency, stability and attitude of the individual to their behavior. On the other hand, ethnic or national origin, religion, race, gender, language, country, education, occupation, age, family, status are common elements for culture. Such categories represent certain social constructions of culture, they give a sense of cultural identity. To improve academic performance, educators can use information about cultural identity to create a supportive learning environment [1].

Studies of students with excellent academic performance, which show that in those educational institutions where there is a careful and attentive attitude to the cultural identity of students and their identity, because these institutions use approaches that take into account the social and cultural experience of students. It follows from this that teachers should have knowledge of the cultural identity of students, which determines their learning characteristics and motivation, and therefore increases their academic performance and self-esteem.

The set of beliefs that make people hold about themselves is called self-esteem. Socializing factors such as peer groups, media, parents and educators influence the development of positive or negative self-esteem in students. Positive self-esteem contributes to the student's academic performance, while poor self-esteem becomes one of the stumbling blocks in how he or she will learn [4]. This challenge requires educators to address the diverse social and academic needs of learners.

As students develop self-esteem during adolescence, they also develop a sense of cultural identity. That is what educators must create opportunities for their wards to succeed by creating a learning environment for them that respects their culture, accepts their diversity, and celebrates their differences. Educators can empower learners by spending more time mentoring rather than managing them. Therefore, it is the teacher's ability to identify with students or understand their cultural identity that is necessary to meet the needs of each student. As such, teachers need to learn as much as possible about their students in order to structure lessons, design teaching materials, and use resources in ways that help all students achieve academic success. In other words, culture is a kind of cement that connects us with others through a common language, goals and lifestyle [8]. 
It should be noted that the cultural background of students is of a great importance. The generation of new knowledge through the production and application of research has introduced the concept as a form of soft power. Using knowledge as power is a development that requires serious thought, since soft power is characterized by competitiveness, dominance and self-interest. There is an assumption that those study groups in which teachers and students share their cultural identity, have a trusting relationship with each other, leads to the involvement of students in the pedagogical process and to greater motivation for the process of acquiring knowledge. Education inevitably brings about change, but the cultural identity of students plays an important role in the transmission of such values.

More recently, the modern world was quite multifaceted and open, since many states were happy to welcome citizens of other countries on their territory. But the coronavirus pandemic has made its own adjustments and at the moment the movement of people and their contacts are strictly limited. Nevertheless, such a situation helps to look anew at one's own environment, to look at many aspects in a new way, and in the future such experience will make the cultural identity of people more complex and multi-layered and will enrich their pedagogical and behavioral experience.

\section{Conclusions}

There are many reasons for introducing cultural identity into today's educational society. Multiculturalism is an undeniably important fact of life. That is why students acquire the skills, knowledge and abilities of how to cultivate tolerance, patience and openness to new information and people, as well as how to learn how to survive in a completely different environment, and this experience is incredibly important.

1. As a result of this article, we can say that identity is not a static, but a socio-dynamic, racial and historical construct.

2. In all interpretations or definitions of "culture" there is a need to maintain and increase the motivation for learning of students.

3. To improve academic performance, educators should use data on the cultural identity of students to create a comfortable learning environment.

4. The cultural background of the student is the key to understanding his or her personality.

5. The relationship between teacher and learners is the key to high motivation and, consequently, academic performance.

6. Developing positive self-esteem in students helps to develop their cultural identity.

7. Cultural identity is a continuous process that develops throughout a person's life.

\section{References}

1. O.A. Voronina, Philosophical Thought, 7 (2019), https://nbpublish.com

2. A. N. Dzhurinskii, Comparative education. Challenges of the XXI century (M.: Promethei, (2014)

3. T.A. Zhukova, M. Schrenk, Young scientist, 5.6 (109.6) (2016)

4. L.A. Kamalova, A.R. Valiullina, A collection of articles of the International Scientific and Practical Conference. - CNS Science and Education (2019)

5. V.S. Malakhov, Multiculturalism and the transformation of post-Soviet societies (Moscow: Institute of Ethnology and Anthropology RAS 2002)

6. A.V. Popov, Proceedings of the St. Petersburg State University of Culture and Arts, 199 (2013) 
7. V.Y. Smorgunova, Bulletin of Omsk University, 1 (2013)

8. I.A. Unshanova, Bulletin of the Novgorod State University, 27, (2004)

9. N. Hopkins, Political Psychology, 2 (2011), http://search.ebscohost.com

10. Levin Shana, Miriam Matthews, Serge Guimond, Jim Sidanius, Felicia Pratto, Nour Kteily, Eileen V. Pitpitan, and Tessa Dover, Journal of Experimental Social Psychology 48 (1), http://www.sciencedirect.com 